\title{
Publisher Correction: Distributing the load with machine learning
}

\section{Ankita Anirban}

Nature Reviews Physics (2020) https://doi.org/10.1038/s42254-020-0176-6 Published online 08 April 2020

In the original version of the article, it was incorrectly stated that natural language processing was used to pick out key terms from proposals and match them to referees' self-reported areas of expertise. Rather, an algorithm was used to find expert referees based on their publication record. The algorithm results matched self-reported expertise well, with an $80 \%$ success rate of removing researchers with no expertise. This has been corrected in the HTML and PDF versions of the manuscript.

https://doi.org/10.1038/s42254-020-0180-x I Published online 15 April 2020

(๑) Springer Nature Limited 2020 